\title{
The status and potential of using controlled parentage in operational reforestation in New Brunswick
}

\author{
By G.W. Adams ${ }^{1}$ and K.J. Tosh ${ }^{2}$
}

Tree improvement programs began in New Brunswick in the 1970 s, and, by the early 1990 s, most of the seed used in reforestation was from seed orchards. Initial research such as fertilizer trials and other flower induction methods focussed on increasing seed orchard yields. Trials have also been established to investigate parental contribution to seed orchard production. As the New Brunswick Tree Improvement Council breeding programs advance into the second generation, two new approaches have been developed to capture genetic gain more efficiently. The use of controlled breeding followed by vegetative multiplication of black spruce has been adopted operationally by J.D. Irving, Limited, and a jack pine meadow orchard has been established by the New Brunswick Department of Natural Resources and Energy. This paper presents an overview of these programs and the future challenges of using controlled parentage in operational reforestation stock production.

\section{Introduction}

Conifer tree improvement programs began in New Brunswick in 1976 with the formation of the New Brunswick Tree Improvement Council (NBTIC). Plus tree selection and seed orchard establishment proceeded rapidly, and, by the late 1980s, substantial quantities of genetically improved seed were produced by NBTIC members. By the early 1990s, seed for all nursery stock production for most of the main reforestation species (black spruce, white spruce, jack pine and tamarack) was being harvested in seed orchards. Research into productivity and genetic efficiency in traditional seed orchards has been conducted in New Brunswick. The initial focus was largely on increasing cone crops for nursery production as well as to facilitate breeding. Research was conducted to optimize rates and timing of nitrogen fertilization to increase flowering, and operational procedures were developed (Simpson and Smith 1988). Accelerated growth procedures and refinements to flower induction techniques using gibberellic acid (GA4/7) were also investigated, initially to accelerate tree breeding programs (Greenwood et al. 1991), but more recently for increasing operational seed production (Greenwood $e t$ al. 1993).

\section{Rationale for New Approaches}

As seed orchards began to produce large quantities of cones, studies were conducted to determine to what degree the

IJ.D. Irving, Limited, Sussex Tree Nursery, 181 Aiton Rd, Four Corners, Sussex, New Brunswick, E4G 2V5.

${ }^{2}$ New Brunswick Dept. of Natural Resources and Energy, Kingsclear Nursery, 3732 Route 2 Hwy, Islandview, New Brunswick, E3E 1G3.
Les programmes d'amélioration génétique ont débuté au Nouveau-Brunswick dans les années 70, et, dès le début des années 90, la plupart des semences utilisées en reboisement provenait des vergers à graines. La recherche initiale tels les essais de fertilisation et autres méthode d'induction de la floraison portait sur les rendements sans cesse croissants des vergers à graines. Des essais ont été également entrepris pour étudier l'apport des parents en matière de production de vergers à graines. À mesure que les programmes de croisement du Conseil d'amélioration génétique du Nouveau-Brunswick progressaient au sein de la deuxième génération d'individus, deux nouvelles approches furent élaborées pour saisir plus efficacement le gain génétique. L'utilisation de la fertilisation contrôlée suivie de la multiplication végétative de l'épinette noire est devenue une mesure opérationnelle chez J.D. Irving, Limited, et un verger de pin gris a été mis en place par le ministère des Ressources naturelles et de l'Énergie du NouveauBrunswick. Cet article présente un sommaire de ces programmes ainsi que des défis à venir dans l'utilisation de sources contrôlées pour la production opérationnelle de stocks de reboisement. seed produced in clonal orchards reflect the genetic potential of the clones in the orchard. The main factors considered included male and female flowering phenology as it relates to random mating, pollen contamination from outside the orchards and the variation in reproductive output across clones. Flower phenology for most of the conifer species is compressed in the Maritimes with female strobili from most clones being receptive within a one week period. Timing of pollen shedding for most clones occurs within a similar time frame (Adams 1992a). Although a few clones are classed as very early or very late, this aspect is not a major problem in orchard management. Background pollen contamination levels have been assessed in a number of seed orchards (Caron 1992, Adams 1992a, Simpson et al. 1992). Caron (1992) found levels of contamination in young black spruce

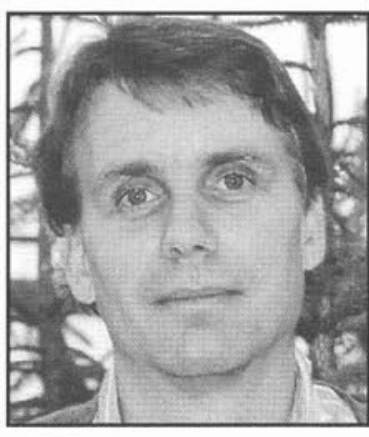

G.W. Adams

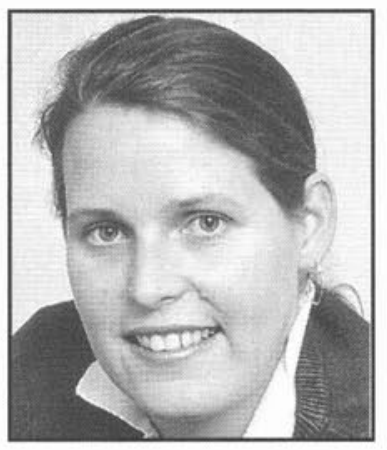

K.J. Tosh seedling seed orchards ranging from $28 \%$ to $83 \%$, which are consistent with findings from many other studies (Lowe and Wheeler 1993). Pollen contamination at these rates will seriously erode the potential genetic gain from the seed orchard. 


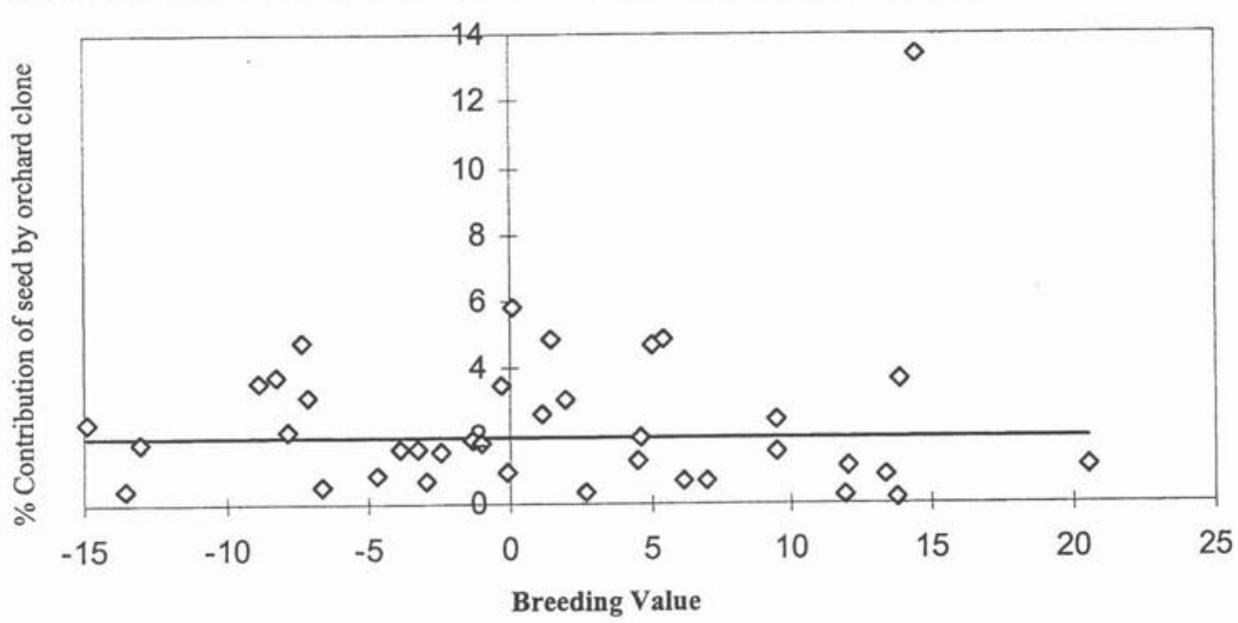

Fig. 1. Breeding value of white spruce clones versus seed contribution to orchard mix in a J.D. Irving Limited seed orchard. The axis at the $2 \%$ level indicates balanced contribution. Points above the line are over contributing clones and those below are under contributors.

Many seed orchards are now considered to be in full seed production, and in the last few years, assessments of variation in seed production across clones have been made (Adams and Kunze 1996, Lafferty 1997). Substantial variation has been observed for seed production and the same is undoubtably true for pollen production. Percent seed contribution of individual clones to overall orchard collections ranged from a fraction of a percent to $6 \%$ for black spruce and $14 \%$ for white spruce (Adams and Kunze 1996). When breeding value information from progeny tests is superimposed on clonal rankings for seed production, the importance of reproductive output as it relates to realizing genetic gain from the seed orchard is apparent. This is illustrated in Figure 1, where the percent seed contribution of individual clones in a white spruce seed orchard from a study by Adams and Kunze (1996) was plotted against breeding values for height from polycross tests. Fifty clones were represented in this study so if clones contributed equally, each would produce $2 \%$ of the seed. Of the 50 clones, breeding value estimates have been made for 38. Data points in Figure 1 above the $2 \%$ line can be classed as over-contributors and points below the line are under-contributors. We are not concerned with clones on the negative side of the breeding value axis because these will be rogued. The main area of interest on Figure 1 is those clones which fall below the $2 \%$ line which also have positive breeding values. There was no significant correlation between percent seed contribution and breeding value $\left(\mathrm{R}^{2}=0.008\right)$ but seven out of the ten clones with the highest breeding values are under-contributors. This illustrates an example of the inefficiencies of traditional seed orchard breeding.

Second generation selection of black spruce and jack pine in open-pollinated family tests began in 1989. The goal of NBTIC was to assemble a breeding population of 400 trees by selecting the best individual from each of the top third of first generation families in black spruce and top half of families in jack pine. Traditional clonal seed orchards were established from a subset of selections taken from the top $10 \%$ of families. It was recognized in the early 1990 s that we had a range of new tools such as accelerated breeding techniques, flower induction and early testing which could be utilized to capture genetic gain more efficiently. A workshop was held in 1991 during which various options were discussed, including indoor seed orchards (Ross 1992), meadow orchards as practised in New Zealand (Powell 1992) and indoor breeding with vegetative multiplication (Adams 1992b). Two of these new approaches have been implemented in New Brunswick since that time. The New Brunswick Department of Natural Resources and Energy (NBDNRE) has been pursuing the development of a meadow orchard for jack pine while J.D. Irving, Limited (JDI) has been bringing controlled breeding and vegetative propagation into operational use. Each approach is described in the following sections.

\section{Controlled Breeding and Vegetative Multiplication of Spruces}

This approach involves controlled breeding among individuals with high breeding values followed by vegetative multiplication of seedlings from these controlled crosses by rooting of cuttings. Some of the best examples of this method in use today for conifers are found in New Zealand with radiata pine (Menzies 1994), in the UK with Sitka spruce (Lee, UK Forestry Commission, pers. comm.) and Douglas-fir in Washington (Ritchie 1996). In some cases, vegetative multiplication is also used in situations where seed production is a problem as with yellow cedar (Russell 1993). The advanced state of the black spruce breeding program in New Brunswick and its amenity to rooting of cuttings have made this species a good candidate for initial efforts using controlled breeding followed by vegetative multiplication (Park et al. 1993). This type of production system will also be appropriate for white spruce and Norway spruce.

Operationally, vegetative multiplication of black spruce begins with controlled pollination in the breeding hall, clone bank or seed orchard. Accelerated growth and indoor culture of several ramets of new second generation selections are very effective techniques for producing early flower crops. Polycross breeding is performed on selections in the family tests to speed 


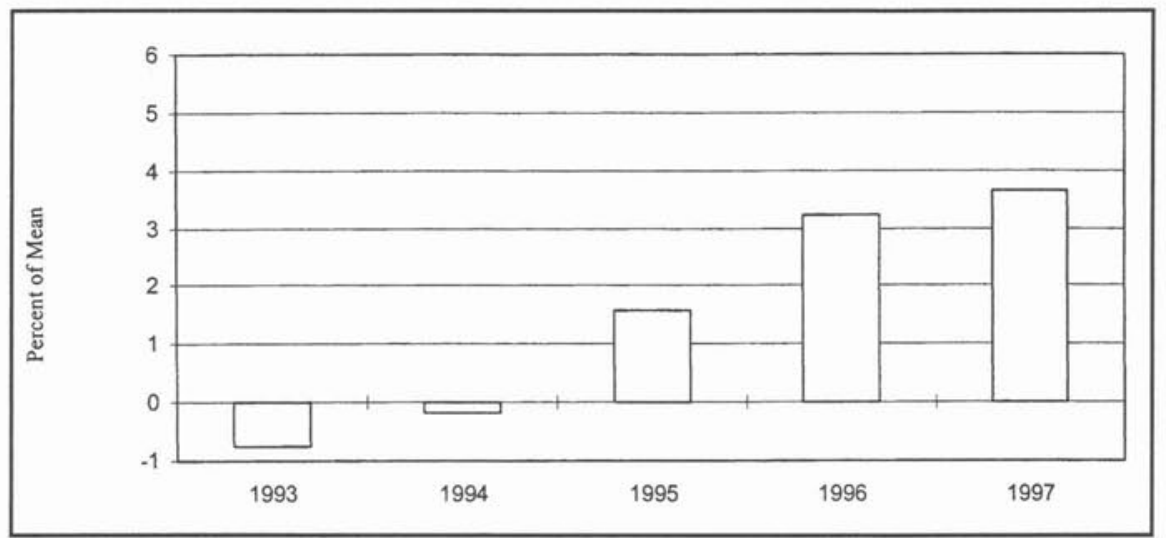

Fig. 2. Percent height superiority of parents used to produce hedge stock by year compared to average of second generation selections based on 5 year height in polycross test. up the testing process and the resulting polycross tests are evaluated to obtain breeding values. Preliminary farm-field test results are commonly available three to four years after planting, and the standard field test results are available within an additional three years. By the time results become available, the grafts of the selections are flowering in the breeding hall and controlled-crossing of high breeding value parents can be conducted. In the spring, prior to reproductive bud flushing, female and male flowers are inventoried, and, based on breeding value, 20 to 30 full-sib crosses are made. In order to support a cutting production program of 1 million per year, 5000 viable seeds must be produced each year. Seeds are sown in containers by full-sib family in February and seedlings are potted into 8 litre pots in early summer. Approximately 25 cuttings can be obtained from each stock plant in the following year, with the numbers increasing annually. Stock plants are held for 4 years, and, on average, each produces 300 cuttings.

Rooted cuttings may be produced using dormant (hard) or actively growing, semi-lignified (soft) cuttings. Hard cuttings are inserted in containers (Multipot 67s) in February and placed in heated greenhouses. Rooting medium is a $3: 1 \mathrm{mix}$ of peatmoss and vermiculite. Fog is used to maintain high humidity without saturating the rooting medium. These cuttings usually root over a three month period and are moved to outdoor shade houses or cold frames in late June. Cuttings are shipped to reforestation sites the following spring. Soft cuttings are harvested in July and rooted in the same manner as hard cuttings. These rooted cuttings are overwintered in cold frames and are shipped to reforestation sites in August of the following year. Overall rooting is usually in the 80 to $90 \%$ range and is influenced by family effects. From the nursery production standpoint, therefore, there are advantages to growing by family block regardless of the field deployment strategy.

The main advantages of this type of production system is the degree of flexibility with respect to changing the genetic composition of operational reforestation stock. Controlled crosses can be made every year, and the most recent information can be used to select parents with the highest breeding values for controlled breeding. In addition, certain families can also be easily culled from the production hedges when required. Figure 2 illustrates the percent superiority of parents used in full-sib crosses compared to the average of second generation black spruce selections over a five year period. No second generation test information was available until the third year when five year measurements were made of the first NBTIC second generation polycross test. The percent superiority of parents used in crosses has increased since then.

\section{Meadow Orchards for Jack Pine}

The concept of meadow orchards as an alternative to conventional seed orchards was first introduced in New Zealand for radiata pine (Sweet and Krugman 1977). The rationale of meadow orchards is to increase cost effectiveness of seed production while maximizing genetic gain. In the meadow orchard approach, instead of managing large numbers of trees over a large area, trees are planted at closer spacing and in clonal rows. The advantages to this approach are that all the seed produced will be of controlled pollination origin, either by supplemental mass pollination (SMP) or controlled pollination, thereby eliminating the problems of pollen contamination and the concern of unequal parental contribution. Another advantage of meadow seed orchards is that, by applying accelerated growth regimes to grafts, the time to seed production can be reduced. The smaller number of grafts used in a meadow orchard would make this technique operationally feasible. Planting grafts in clonal rows allows for genotypes to be easily replaced as genetic testing information becomes available.

The use of SMP has been tried on a limited scale in the Maritimes by a number of NBTIC members. The NBDNRE has conducted several experiments, and although small, the results have been promising. Work to date has concentrated mainly on increasing filled seeds per cone. A trial in 1988 in a 5 year old NBDNRE white spruce clonal orchard found that the number of full seeds per cone increased from 25 to 38 full seeds per cone. A small crew walked around the 3 hectare orchard and applied pollen using a powder insufflator. Another trial in 1992, using the same white spruce orchard, yielded even better results. The seven year old grafts receiving SMP yielded 39 seeds per cone whereas the open-pollinated area only yielded 18 seeds per cone. A total of only 4 hours was required to do the SMP in the orchard. This resulted in over a $50 \%$ increase in seed yield compared to open-pollinated orchards.

With the limited SMP trials in New Brunswick and elsewhere in the Maritimes, it is very difficult to establish a cost/benefit ratio. Even in New Zealand where SMP and controlled pollination techniques are used extensively, there is little information on the cost/benefits. The potential for increased genetic gain using controlled pollination is well recognized and 
Table 1. Growing schedule for accelerated growth of jack pine grafts for meadow orchard.

\begin{tabular}{ll}
\hline Date & Activity \\
\hline January 1993 & Graft jack pine scion \\
January-May 1993 & Grafts flush and grow in greenhouse \\
May-June 1993 & Artificial cold treatment \\
June-July 1993 & Second growth flush \\
August-December 1993 & Natural cold treatment \\
January-May 1994 & Third growth flush \\
June 1994 & Outplant in meadow orchard \\
\hline
\end{tabular}

is considered an important component of the management of orchards (Vincent, FRI, pers. comm.). In 1996 over 480,000 pollen isolation bags were used nationally in New Zealand. This represents a large commitment on the part of New Zealand companies that manage the radiata pine orchards.

NBDNRE established a prototype meadow orchard as part of a Miniaturized Seed Orchard Project funded through the Canada-New Brunswick Cooperation Agreement on Forest Development (Smith and Powell 1992). The jack pine orchard was planted at the Kingsclear Provincial Forest Nursery, near Fredericton. A total of 25 clones were used from the top 40 orchard clones from second generation selections. Twenty five ramets per clone were grafted in the winter of 1993. Thus, 625 grafts were available for planting in the meadow orchard. Growth of the grafts was accelerated by subjecting them to a second growth cycle in the greenhouse during the winter months. The trees were then planted in clonal rows at a spacing of $1.5 \mathrm{~m} \times 2.5 \mathrm{~m}$ in June of 1994 . Timing of treatments is described in Table 1. The grafts are now well established and have reached a size where an intensive management plan is applied. Pollen was collected from the top 20 to 25 jack pine second generation clones based on early greenhouse testing and the clones in the orchard were pollinated using SMP. Other studies, such as topping and pruning of the jack pine grafts, are planned.

As the meadow orchard is relatively new and supplementary pollinations are only now beginning, the cost of performing SMP on an operational scale is uncertain. However, because the area of this orchard is small and the clonal rows make it easier to take into account phenological differences among clones, it is felt that SMP is operationally feasible and practical. The volume gain from first generation rogued and second generation orchards is estimated to be $10 \%$ and $17 \%$, respectively. The use of SMP using top performing clones within the second generation population should increase the volume gains that are currently estimated for open-pollinated second generation orchards.

\section{Future Challenges}

The challenges with respect to both of the described approaches to controlling parentage of reforestation stock are essentially the same. We can see clearly how greater genetic gain can be achieved through these approaches, however we need to do considerable work on the practical aspects of economics and logistics. Production of reforestation stock using these methods will not completely replace traditional seed orchards, rather they should be viewed at this time as a tool to produce planting stock with a higher level of genetic improvement for use on the best sites. Costs to produce rooted cuttings are generally around double the cost of producing seedlings, so work needs to be done on increasing production efficiency. Related to logistics, there is a fairly short window for striking cuttings in the summer when production costs are least because no heating is required. The cuttings must be semilignified but they must also have enough time to root before over-wintering. Efficiency must be maximized so that excessively large crew sizes are not required to meet production goals. Another major component which requires optimizing is hedge stock management since maintaining hedges is a major cost in vegetative propagation programs. Issues such as the optimum useful life and spacing for hedge plants are examples of areas which require research. Over time, mechanization will be very desirable for harvesting and striking cuttings.

Similar issues are involved in the meadow orchard concept. Most of the production activities will have to be conducted in a very narrow time frame. For controlled pollination, bagging and pollination occurs within a two week period. Relatively few jack pine flowers can be isolated in one pollination bag compared to spruce. High rates of conelet abortion have frequently been observed for jack pine. In the Maritimes, SMP has only been investigated as a means of increasing filled seed, so if this technique is to be used in meadow orchards, the reliability for producing the desired cross will need to be examined. Also, cost and production information for meadow orchards of jack pine will have to be developed as the prototype orchard produces seed.

Deployment strategies need to be developed for reforestation stock produced by both controlled pollination with vegetative multiplication and meadow orchard methods. The number of parents in operational production programs will not necessarily be any less than in a traditional seed orchard; however, they will be selected from the second generation breeding population based on the most current genetic test information. Most likely, there will be considerable turnover of production parents within the generation compared to seed orchards. At the landscape level, we will need to make decisions and develop guidelines on how to use this material, i.e., should families be mixed or deployed in mosaics of family blocks? Trials were initiated for black spruce in 1997 to examine this issue.

\section{References}

Adams, G.W. 1992a. Pollen monitoring studies in a J.D. Irving Ltd. seed orchard and orchard management implications. pp. 21-26 In: Proc. of Challenges in pollen dispersal and pollen contamination workshop, F. Di-Giovanni and D. Joyce, eds. February, 1992, Egbert, Ontario. Environment Canada Rep. CCAD-92-008.

Adams, G.W. 1992b. Seed production - indoors versus outdoors. p. 23 (Abs.) In: Proc. 4th Annual Maritime Seed Orchard Managers Workshop, R.F. Smith and L.D. Phillips, eds., 22-24 October 1991, Edmunston, NB.

Adams, G.W. and H.A. Kunze. 1996. Clonal variation in cone and seed production in black and white spruce seed orchards and management implication. For. Chron. 72(5): 475-480.

Caron, G.E. 1992. Pollen dispersal and contamination studies in New Brunswick and Quebec. pp. 35-39 In: Proc. of Challenges in pollen dispersal and contamination workshop, F. Di-Giovanni and D. Joyce, eds. February, 1992, Egbert, Ontario. Environment Canada Rep. CCAD-92-008.

Greenwood, M.S., G.W. Adams and M. Gillespie. 1991. Stimulation of flowering by grafted black spruce and white spruce: a comparative study of the effects of gibberellin A4/7, cultural treatments 
and environment. Can. J. For. Res. 21: 395-400.

Greenwood, M.S., G.W. Adams and S. Kempton. 1993. Using recent advances in the control of reproductive development to increase genetic gain. pp. 19-25 In: Proc. 24th Meeting of the Canadian Tree Improvement Association, J. Lavereau, ed. 15-19 August 1993, Fredericton, NB.

Lafferty, L.M. 1997. Clonal variation in cone and seed production in a second generation jack pine orchard. University of New Brunswick, Unpublished B.Sc.F. thesis, 18 p.

Lowe, W.J. and N.C. Wheeler. 1993. Pollen contamination in seed orchards. pp. 49-54 In: Advances in Pollen Management, U.S. Dept. of Agriculture, Forest Service, Agriculture Handbook 698.

Menzies, M.I. 1994. Propagation of radiata pine plants for plantation forestry. pp. 382-388 In: Combined Proc. of International Plant Propagators Society, Vol. 44.

Park, Y.S., J.D. Simpson, G.W. Adams, E.K. Morgenstern and T.J. Mullin. 1993. An updated strategy for black spruce (Picea mariana (Mill.) B.S.P.) in New Brunswick. pp. 41-54 In: Proc. Workshop on Breeding Strategies of Important Tree Species in Canada, Y.S. Park and G.W. Adams, eds. 18 August 1993. Natural Resources Canada Inf. Rep. M-X-186E. 54 pp.

Powell, G. 1992. Meadow orchards. p. 22 (Abs.) In: Proc. 4th Annual Maritime Seed orchard Managers Meeting, R.F. Smith and L.D. Phillips, eds., 22-24 October 1991, Edmunston, NB.

Ritchie, G.A. 1996. Operational use of vegetative propagation in forestry: world overview of cloning and bulking. pp. 192-197 In: National Proceedings, Forest and Conservation Nursery Associations. Gen. Tech. Rep. PNW-GTR-389. Portland Ore.: U.S. Dept. of Ag., Forest Service, Pacific Northwest Research Station.
Ross, S. 1992. Improving seed production efficiency in seed orchards - opportunity and experiences in British Columbia. p. 20 (Abs.) In: Proc. 4th Annual Maritime Seed Orchard Managers Workshop, R.F. Smith and L.D. Phillips, eds., 22-24 October 1991, Edmunston, NB.

Russell, J.H. 1993. Incorporating clones into tree improvement strategies: two contrasting examples from British Columbia. pp. 10-16 In: Proc. 24th Meeting of the Canadian Tree Improvement Association, J. Lavereau, ed., 15-19 August 1993, Fredericton, NB.

Simpson, J.D. and R.F. Smith. 1988. A manual for forest tree seed orchard management in the Maritimes. Canadian Forestry Service - Maritimes, Inf. Rep. M-X-167.

Simpson, J.D., M. Fullarton and P. Nitschke. 1992. An overview of pollen contamination studies by the New Brunswick and Nova Scotia Departments of Natural Resources. In: Proc. of Challenges in pollen dispersal and contamination workshop, F. Di-Giovanni, eds. February, 1992, Egbert, Ontario. Environment Canada Rep. CCAD-92-008. Smith, R.F. and G.R. Powell. 1992. Is there a place for alternatives to conventional seed orchards in the Maritimes. Forestry Canada, Maritimes Region, R \& D Technical Note Number 4, 4 p.

Sweet, G.B. and G.L. Krugman. 1977. Flowering and seed production problems - and a new concept of seed orchards. pp. 749-759 In: Proc. 3rd World Consultation on Forest Tree Breeding, Canberra, Australia. 